\title{
Life Balance of Mothers of Children with Cerebral Palsy
}

\section{Sepideh Nazi ${ }^{1}$, Narges Shafaroodi ${ }^{*}$, Laleh Lajevardi' ${ }^{1}$, Afsoon Hassani Mehraban ${ }^{1}$, Farzaneh Yazdani ${ }^{2}$, Samaneh Hosseinzadeh ${ }^{3}$}

\footnotetext{
${ }^{1}$ Department of Occupational Therapy, School of Rehabilitation Sciences, Iran University of Medical Sciences, Tehran, Iran ${ }^{2}$ Faculty of Health and Life Sciences, Oxford Brookes University, Oxford, UK

${ }^{3}$ Department of Statistics and Computer Sciences, University of Social Welfare and Rehabilitation Sciences, Tehran, Iran

Email: *Shafarodi.n@iums.ac.ir
}

How to cite this paper: Nazi, S., Shafaroodi, N., Lajevardi, L., Mehraban, A.H., Yazdani, F. and Hosseinzadeh, S. (2017) Life Balance of Mothers of Children with Cerebral Palsy. International Journal of Clinical Medicine, 8, 583-594.

https://doi.org/10.4236/ijcm.2017.811055

Received: April 25, 2017

Accepted: November 13, 2017

Published: November 16, 2017

Copyright $\odot 2017$ by authors and Scientific Research Publishing Inc. This work is licensed under the Creative Commons Attribution International License (CC BY 4.0).

http://creativecommons.org/licenses/by/4.0/

\begin{abstract}
Purpose: Having the child with Cerebral palsy is a very stressful experience for the family that could affect daily patterns and routines, habits, needs and occupational performances of all family members specially mothers. This study aimed to investigate life balance of mothers of children with Cerebral palsy (MCCPs) based on the Life Balance Model. Method: Fifty MCCPs aged 3 to 9 years with sample convenient method participated in this descriptive and cross-sectional study. The Severity of cerebral palsy was determined by Gross Motor Function Classification System (GMFCS) and Manual Ability Classification System (MACS) and the life balance of mothers was evaluated by Persian version of the LBI (P_LBI). The collected data were evaluated and analyzed using SPSS software. Results: The total mean score of LBI and its subscales showed that there is no balanced or very balanced life in mothers and they could be categorized to unbalanced $(\mathrm{n}=21)$ and very unbalanced $(\mathrm{n}=29)$. The total mean score of LBI was 1.46. $\chi^{2}$ test revealed statistically significant difference between two categories (unbalanced and very unbalanced) of mothers regarding GMFCS level $(p=0.009)$. Also, the total mean score of LBI and its subscales showed no significant difference between two categories (unbalanced and very unbalanced) regarding mother job and age and child age $(p>0.05)$ but it has significant difference regarding mother education $(p=0.009)$. Evaluation of the results of LBI and its different subscales indicated that the life balance at balanced or very balanced levels was not observed in any of the studied mothers, and they could be categorized in 2 groups of unbalanced (21 mothers ) and very unbalanced (29 mothers) (Table 2). Discussion: Based on the result of this study, mothers of Cerebral Palsy do not experience balanced life and this feeling of unbalance is related to the level of their child's disability. Thus, it is necessary
\end{abstract}


to consider this fact in family-centered evaluations and Occupational therapy interventions.

\section{Keywords}

Life Balance, Cerebral Palsy, Main Caregiver

\section{Introduction}

Among the large variety of childhood developmental disabilities, Cerebral Palsy (CP) is considered to be the common physical disability affecting the motor, sensory, cognitive and functional development of children [1] [2]. Children with $\mathrm{CP}$ have major limitations in engagement and participation in the daily activities such as eating, wearing cloths, bathing, and moving. Therefore, they need further and longer cares, compared with the normal children [3]. Having a child with developmental disability, such as $\mathrm{CP}$, influences the habits and needs of the children. Also, due to close relationship between family members, such conditions affect the quality of life, daily and routine patterns, and also habits and needs of other family members, specifically the mothers [4]. Living in today's modern era requires doing different activities and occupations: work, rest, leisure and self care to meet personal, social, and familial needs [5]. To take care of a child with $\mathrm{CP}$ causes parents, especially mothers, ignore other aspects of life and do not experience some degrees of satisfaction in their daily activities [3] [4] [6].

The family-centered service is a supporting approach which emphasizes on the relationship between parents and supporting services [7]. Family-centered services rely on the family system theory and explain the relationship between the welfare of the family and the child, and emphasize on power, sources, and abilities of children and the family [8] [9] [10].

According to the approach of family-centered services, any intervention in the caregivers may improve and promote the quality of life in the whole family and also, assessment of the family system and caregivers from different aspects may improve providing the services for the children with disabilities [10]. Although it is necessary to raise knowledge about the negative outcomes of $\mathrm{CP}$ on the child and family to plan appropriate interventions for the medical team members such as occupational therapists, there are a few studies on the outcomes of having a child with CP on the life balance of caregivers, in Iran and worldwide. Studies reported the moderate quality of life of mothers of children with $\mathrm{CP}$, and the negative effect of severity of CP and stress on the quality of life [3] [4] [11] [12] [13] [14].

Also, MCCPs face imbalance in different occupations and experience lower satisfaction in time management as they spend a lot of time to take care of their children [6]. Therefore, the risk of mental complications increases in the families over the time, which in turn, disrupts family relaxation and satisfaction, prevents 
family members from normal life and their roles in the family, and exposes them to the risk of inconsistent and inefficient copping patterns [11].

In the recent years, based on the change of general attitudes toward balance in life, the concentration of occupational therapy researchers shifted from balance among different aspects of work, rest, and leisure to life balance [5] [15]. One of the proposed models that were developed by Matuska and Christiansen (2008) is the Life Balance Model (LBM) [15]. The life balance, according to this model, is a satisfactory pattern of occupations and daily activities, which maintains individual's health under the current life conditions and personal context; it is significant and stable. In fact, this model emphasizes on 5 primary and basic need-based dimensions (health, relationships, challenges, identity, and efficient use of time), which by the recognition of such needs human experiences more satisfaction, less stress, more meaning and finally balance in life [15]. Since there is little information on the life balance of caregivers of children with $\mathrm{CP}$, the current study aimed at evaluating the life balance of the main caregivers of children with $\mathrm{CP}$. To achieve the goal, the Life Balance Inventory (LBI) was translated into Persian, and then, the life balance status of the main caregivers of children with CP was assessed using the P_LBI.

\section{Materials \& Methods}

This cross-sectional and descriptive study was carried out from June 2016 to October 2016.

\subsection{Participants}

A convenience sample of 50 Mothers of Children with Cerebral Palsy (MCCPs) who met the inclusion criteria were recruited from pediatrics Occupational therapy clinics of Iran University of Medical Sciences, Tehran, Iran. Informed consent was obtained from all the respondents. Inclusion criteria for selection were: 1) MCCPs; 2) Having ability to read and understand Persian; 3) Being aged between 25 - 45 years; 4) Being married; 5) having a child with CP with the age of 3 to 9; with 3 to 5 level of gross motor function based on GMFCS and 3 to 5 level of manual ability based on MACS; 6) un existence of another disabled or sick individual to take care of; 7) Absence of the history and currently diagnosis of chronic physical and psychological disease.

Cases of CP were classified using the Swedish classification [16]. In this study, the researchers took into consideration only spastic children based on neurologist diagnosis.

\subsection{Procedure}

The data were collected through the Persian version of the LBI (P_LBI), a demographic questionnaire specifically designed for recording sociodemographic factors of mothers, medical history of mothers, medical and developmental history of child such as clinical types of $\mathrm{CP}$, level of gross motor function based on 
GMFCS, level of manual ability based on MACS and any concomitant problems of children with CP.

\subsection{Instruments}

The LBI is an instrument to measure life balance. Its theoretical foundation is the Life Balance Model. It measures the degree of congruence between desired and actual time use in 53 activity categories and four subscales. A total average score across all items and four subscales correspond to the four need-based dimensions of the Life Balance Model: health, relationship, identity, and Challenge are generated. LBI has demonstrated good internal consistency (Cronbach's alpha 0.89 and 0.97 , respectively). Scoring criteria for the LBI is defined as: 1.0 1.5-very unbalanced, 1.5 - 2.0-unbalanced, 2.0 - 2.5-moderately balanced, 2.5 3.0-very balanced [17].

(Persian LBI) P_LBI:

To be used in this study, Based on the International Quality of Life Assessment (IQOLA) guidelines, the English version of the LBI was translated into Persian language. Permission was taken from the original developer to translate the LBI from English to Persian. The IQOLA project was established in 1991 with the goal of developing validated translations of a health status questionnaire as required for their use internationally in order to avoid bias in interpretation and adaptation [18] [19]. The sequential order of translation of LBI based on IQOLA protocol was as follow: Forward translation of the items of the English version of the LBI into Persian language by two native Persian speakers with fluency in English (Translator A and B), harmonization and reconciliation of the two different translations and producing harmonized translation, backward translation into English by two professional translators (Translator C and D) for conceptual equivalence with the original source version of LBI, assessing through expert Panel of 8 Occupational therapists with the 5 years experience in pediatric field for comprehensibility and ambiguity on the difficulty and quality rating in terms of clarity, common language usage, and conceptual equivalence. At the end, the final Persian version of LBI was sent to developer for confirmation.

\section{GMFCS:}

GMFCS scale is a scale specific to children with CP and composed of 5 levels according to gross motor functions: 1) Walks without Limitations; 2) Walks with Limitations; 3) Walks Using a Hand-Held Mobility Device; 4) Self-Mobility with Limitations; May Use powered mobility; 5) Transported in a Manual Wheelchair [20].

\section{MACS:}

MACS scale is a scale specific to children with CP and composed of 5 levels according to handling of objects in daily activities: 1) Handles objects easily and successfully; 2) Handles most objects but with somewhat reduced quality and/or speed of achievement; 3) Handles objects with difficulty; needs help to prepare and/or modify activities; 4) Handles a limited selection of easily managed objects 
in adapted situations; 5) Does not handle objects and has severely limited ability to perform even simple actions, requires total assistance [21].

This study was approved by the Ethical Review Committee, School of Rehabilitation, Iran University of Medical Sciences, Tehran, Iran.

\subsection{Data Analysis}

The collected data were analyzed by the SPSS software version 16 . The demographic data of all participants and the means of total score and subscales were calculated. To understand the normal distribution of each variable, the Kolmogorove Smirnoff test was used. Then, the independent t-test or Chi-square test was used for comparing the life balance of the mothers in relation to their educational level and job, mother and child age, and GMFCS and MACS score of their children.

\section{Results}

A total of 50 MCCPs, with the age range of 26 to 45 years, were enrolled in the current study; the population of children with CP included 31 males and $19 \mathrm{fe}$ males with the age range of 36 to 109 months. The frequency of the distribution of CP indicated 25 children with diplegia, 18 with quadriplegia, and 7 with hemiplegia. The severity of motor disability, were classified by GMFCS; moderate to severe level of gross motor function (levels 3 to 5) and MACS; moderate to severe level of manual ability (levels 3 to 5). All children lived with their mothers and fathers, and most of them (36 children) were the 1st child (Table 1).

Evaluation of the results of LBI and its different subscales indicated that the life balance at balanced or very balanced levels were not observed in any of the studied mothers, and they could be categorized in 2 groups of unbalanced ( 21 mothers )and very unbalanced (29 mothers) (Table 2).

For better evaluation of the results, the total score of life balance of mothers were divided into 2 groups of unbalanced and very unbalanced and the comparisons were made based on the assigned classes (Table 3). On the other hand, the balance scores in each subgroup of health, identity, challenges/interests, and

Table 1. The demographic characteristics of participants in the study $(\mathrm{N}=50)$.

\begin{tabular}{|c|c|c|}
\hline \multicolumn{2}{|c|}{ Variable } & Mean (SD) or $n(\%)$ \\
\hline \multicolumn{2}{|c|}{ Mother age } & $34.18(5.013)$ \\
\hline \multicolumn{2}{|c|}{ Child age } & $61.54(21.35)$ \\
\hline \multirow{3}{*}{ Number of children } & 1 & $15(30)$ \\
\hline & 2 & $24(48)$ \\
\hline & 3 & $11(22)$ \\
\hline \multirow{3}{*}{ Type of CP } & Diplegia & $25(50)$ \\
\hline & Quadriplegia & $18(36)$ \\
\hline & Hemiplegia & $7(14)$ \\
\hline
\end{tabular}


Table 2. Descriptive statistics of the LBI $(\mathrm{N}=50)$.

\begin{tabular}{cccc}
\hline LBI & Minimum & Maximum & Mean (SD) \\
\hline Health sub scale & 1.00 & 1.71 & $1.42(0.158)$ \\
Identity sub scale & 1.10 & 1.76 & $1.45(0.176)$ \\
Challenge sub scale & 1.20 & 1.79 & $1.48(0.160)$ \\
Relationship sub scale & 1.20 & 1.91 & $1.50(0.129)$ \\
LBI total score & 1.21 & 1.64 & $1.46(0.112)$ \\
\hline
\end{tabular}

Table 3. The association of maternal LBI and GMFCS, MACS, Level of education and job status $(\mathrm{N}=50)$.

\begin{tabular}{|c|c|c|c|c|c|}
\hline & \multirow[b]{2}{*}{ Variable } & & \multicolumn{2}{|c|}{ LBI } & \multirow[b]{2}{*}{$p$ value } \\
\hline & & & $\begin{array}{c}\text { Unbalanced, } \\
\text { n (\%) }\end{array}$ & $\begin{array}{c}\text { Very unbalanced, } \\
n(\%)\end{array}$ & \\
\hline \multirow{3}{*}{$\begin{array}{l}\text { GMFCS*, } \\
\text { n (\%) }\end{array}$} & Level 3 & $12(24)$ & $10(62.5)$ & $6(37.5)$ & \multirow{3}{*}{0.009} \\
\hline & Level 4 & $25(50)$ & $10(48)$ & $11(52)$ & \\
\hline & Level 5 & $13(26)$ & $1(8)$ & $12(92)$ & \\
\hline \multirow{3}{*}{$\begin{array}{l}\text { MACS }^{* *} \\
\text { n (\%) }\end{array}$} & Level 3 & $29(58)$ & $16(55)$ & $13(45)$ & \multirow{3}{*}{0.003} \\
\hline & Level 4 & $15(30)$ & $5(33)$ & $10(67)$ & \\
\hline & Level 5 & $6(12)$ & $0(0)$ & $6(100)$ & \\
\hline \multirow{4}{*}{$\begin{array}{c}\text { Level of } \\
\text { mother } \\
\text { education, } \\
\mathbf{n}(\%)\end{array}$} & High school & $11(22)$ & $2(18)$ & $9(82)$ & \multirow{4}{*}{0.009} \\
\hline & College & $8(16)$ & $1(12.5)$ & $7(87.5)$ & \\
\hline & BS & $21(42)$ & $10(48)$ & $11(52)$ & \\
\hline & MS & $10(20)$ & $8(80)$ & $2(20)$ & \\
\hline \multirow{3}{*}{$\begin{array}{l}\text { Job status, } \\
\text { n (\%) }\end{array}$} & Full-time & $14(28)$ & $7(50)$ & $7(50)$ & \multirow{3}{*}{0.734} \\
\hline & Part-time & $2(4)$ & $1(50)$ & $1(50)$ & \\
\hline & Household & $34(68)$ & $13(38)$ & $21(62)$ & \\
\hline
\end{tabular}

Notes: ${ }^{\star}$ Gross Motor Function Classification System; ${ }^{* *}$ Manual Ability Classification System.

relationships were also given based on the assigned classes and the comparisons were made based on these classes; due to the high volume of data, only the scores with significant differences were mentioned in the current manuscript.

According to Table 3, the results of Chi-square test in the unbalanced and very unbalanced classes indicated a significant difference between the mean scores of LBI in children's gross motor function ( $p$-value $=0.009$ ) and hand function ( $p$-value $=0.032$ ). To evaluate the difference between the mean scores of subgroups of LBI regarding gross motor function of children, the significant difference was also observed in the subgroups of identity and relationship ( $p$-value $<0.05$ ). Also, there was a significant difference in the subgroup of challenges and interests, regarding the hand function of children ( $p$-value $=0.05$ ).

In addition, results of Chi-square test indicated no significant difference between the mean scores of LBI and its different subgroups regarding mothers' job 
status in unbalanced and very unbalanced classes ( $p$-value $>0.05)$. But, according to Table 3, there was a significant difference between the mean scores of LBI regarding the mothers' level of education ( $p$-value $=0.009$ ).

According to Table 4, there were no significant differences between the mean scores of LBI and its different subgroups in unbalanced and very unbalanced classes regarding the age of mother and child ( $p$-value $>0.05$ ).

\section{Discussion}

The current study aimed at evaluating the life balance of the main caregivers of children with CP, mothers, and its relationship with the level of gross motor disability and hand function in the children. Results of the current study indicated that the life balance of mothers were unbalanced and very unbalanced in the 4 subscales of life balance inventory (health, identity, challenges/interests, and relationships). Rassafiani et al., indicated that mothers of the children with CP do not experience the required life balance in their daily affairs as they spend a lot of time on their children every day, which reduces their satisfaction about time use. Also, MCCPs reported lower satisfaction about their time management skills, compared with the mothers of healthy children [6]. Children with CP, and moderate to severe disabilities, almost need long-term and particular care and attention; since the caregivers of such children spend a lot of time on their regular and specific needs, such as bathing, moving, feeding, giving medical cares, dealing with educational and parenting affairs even in the school, they have limited time to consider their own needs [4]. Most of the mothers in the current study dealt with difficulties to meet their hygienic and health-related needs such as personal hygiene, sleeping, relaxing, exercising, and eating, and were unsatisfied in this regard. Florez and Crowe also reported that the MCCPs have lower quality in their daily and personal affairs and time used [22]. In addition, due to low access to effective urban transportation system and appropriate and cost-effective rehabilitation aids such as wheelchairs in Iran, taking older children with CP to refer to the rehabilitation centers or go to school, etc. is more difficult and needs more time and energy. In the evaluations performed by Kaye et al., mothers of children with CP reported more bodily pain, which may result from lower support from relatives and spouses and impose more physical burden. Such conditions result in experiencing more physical and psychological exhaustion, and consequently, dissatisfaction and lower quality of life in mothers [23]. Projected roles as wife,

Table 4. The association of maternal LBI and child age and mother age.

\begin{tabular}{ccccccc}
\hline Variable & LBI & N & Mean & SD & F & $p$ value \\
\hline \multirow{2}{*}{ Child Age (month) } & Unbalanced & 21 & 33.95 & 5.64 & & \\
& Very unbalanced & 29 & 34.34 & 4.60 & 1.337 & 0.788 \\
& Unbalanced & $\mathbf{2 1}$ & 64.05 & 23.68 & & \\
Mother Age (year) & Very unbalanced & $\mathbf{2 9}$ & 59.72 & 19.74 & & \\
& & & & & \\
\end{tabular}


housework and out of home tasks, and participation in the family favorite activities and programs are a part of identical characteristics of mothers which are being affected by taking care of a child with CP. They should spend less time on the tasks indicating their identical characteristics. Johnson and Deitz reported that mothers of children with special needs spend extra time on taking physical care of their children. But, mothers of healthy children have more participation in outdoor activities [24]. Work and work identity, participation in recreation and leisure activities, and engagement in favorite arts, which involve the challenges/interests subscale, are particularly limited by having a child with CP. Florez and Crowe indicated a significant difference in the time of taking care of children and spending time on recreation and leisure activities between the MCCPs and mothers of healthy children. The difference is exuberated by increasing the age of child [22]. The current study concluded that the type of mothers' activities is associated with having a child with disabilities and the age of the child. Although imbalance was observed in mothers' activities and their satisfaction with life, no significant relationship was observed between the age of child and life balance in mothers.

According to the results of the analyses, relationship with spouse, friends, families, colleagues, and meeting new people, participation in workshops, taking care of other children, even private and intimate marital relations among mothers of children with $\mathrm{CP}$ were greatly restricted as they spent a lot of time to take care of their children with disabilities. Such conditions imposes heavy mental burden on MCCPs and decreases their metal satisfaction and life balance. A significant direct relationship was observed between marital dissatisfaction and the quality of life in parents [25]. Laskar et al., reported more conflicts among family members due to taking care of a child with $\mathrm{CP}$, which may result in further marital complications. Mothers usually spend more time to take care of children and consequently have less time to make intimate contacts and relationships with their spouses [25]. Fathers almost are involved in outdoor affairs and job-related issues, and their verbal relationship with the wives is reduced following the lower intimate contacts and less emotional and sexual supports from the wives; in consequence, the mothers lose their main supportive source and feel lonely and isolation [26]. The current study also showed a significant relationship between the severity of gross motor and hand disability in the children and the life balance in the caregivers. Higher levels of disability in the children increase pressures and life imbalance in the caregiver. Tal-hatu et al., also reported lower health status in MCCPs, which strongly associated with the level of disability in children. Also, a significant relationship was observed between the level of disability in children and the quality of marital performances, stress, and lack of access to social supports in parents, specifically mothers [27].

The study by Gevir et al., was the only study showed different results, compared with those of the current study. They evaluated the different timetabling between MCCPs and mothers of healthy children in the age range below 6 years using Mothers' Time Use Questionnaire. According to their study, a significant relationship was observed between the groups regarding the time spent to the following issues: 
taking care of the child, housekeeping, enjoying leisure, sleeping, resting, and working. Meanwhile, no significant difference was reported between the groups regarding the concept of mothers about enjoyment and significance of other issues [28]. Since children involved in the current study aged 3 to 9 years who need more cares during the early years of school, and they cannot oversight their age-appropriate personal affairs and need regular support, the reason of such differences between MCCPs and mothers of healthy children can be explained.

\section{Conclusion}

During the recent years, particularly since 2009, understanding the role of family in the life of people with disabilities, especially those with $\mathrm{CP}$, the principles of family-centered services and their relationship with the performance improvement, participation, and the quality of life of the child with $\mathrm{CP}$ and the family were more taken into consideration and emphasis. Recent studies indicated the different effects and outcomes of motor disabilities on the child and the family, and consequently the lower quality of life and health status, well-being, and satisfaction in the family. Results of the current study showed the main caregivers of children with CP experience imbalanced or severely imbalanced life, whose level is associated with children's disability, and accordingly feel dissatisfaction. Hence, the occupational therapist can improve the family-centered services through information exchange, and being aware of weaknesses, strengths, and requirements of MCCPs, which in consequence, improves the quality of life in the children.

\section{Acknowledgements}

The author presents a heartful gratitude to all the participants who gave their precious time to this research.

\section{Conflicts of Interest}

There are no conflicts of interest.

\section{References}

[1] Jones, M.W., Morgan, E., Shelton, J.E. and Thorogood, C. (2007) Cerebral Palsy: Introduction and Diagnosis (Part I). Journal of Pediatric Health Care, 21, 146-152. https://doi.org/10.1016/j.pedhc.2006.06.007

[2] Rosenbaum, P., Paneth, N., Leviton, A., Goldstein, M., Bax, M., Damiano, D., et al. (2007) A Report: The Definition and Classification of Cerebral Palsy April 2006. Developmental Medicine \& Child Neurology, 109, 8-14.

[3] Altindag, Ö., Işcan, A., Akcan, S., Koksal, S., Erçin, M. and Ege, L. (2007) Anxiety and Depression Levels in Mothers of Children with Cerebral Palsy. Turkish Journal of Physical Medicine \& Rehabilitation, 53, 1.

[4] Mobarak, R., Khan, N.Z., Munir, S., Zaman, S.S. and McConachie, H. (2000) Predictors of Stress in Mothers of Children with Cerebral Palsy in Bangladesh. Journal of Pediatric Psychology, 25, 427-433. https://doi.org/10.1093/jpepsy/25.6.427

[5] Wilcock, A., Chelin, M., Hall, M., Hamley, N., Morrison, B., Scrivener, L., et al. 
(1997) The Relationship between Occupational Balance and Health: A Pilot Study. Occupational Therapy International, 4, 17-30. https://doi.org/10.1002/oti.45

[6] Rassafiani, M., Kahjoogh, M.A., Hosseini, A. and Sahaf, R. (2012) Time Use in Mothers of Children with Cerebral Palsy: A Comparison Study. Hong Kong Journal of Occupational Therapy, 22, 70-74. https://doi.org/10.1016/j.hkjot.2012.11.001

[7] Rosenbaum, P., King, S., Law, M., King, G. and Evans, J. (1998) Family-Centred Service: A Conceptual Framework and Research Review. Physical \& Occupational Therapy in Pediatrics, 18, 1-20. https://doi.org/10.1080/J006v18n01_01

[8] King, S., Teplicky, R., King, G. and Rosenbaum, P., Eds. (2004) Family-Centered Service for Children with Cerebral Palsy and Their Families: A Review of the Literature. Seminars in Pediatric Neurology, 11, 78-86.

[9] Kruijsen-Terpstra, A.J., Ketelaar, M., Boeije, H., Jongmans, M.J., Gorter, J.W., Verheijden, J., et al. (2014) Parents' Experiences with Physical and Occupational Therapy for Their Young Child with Cerebral Palsy: A Mixed Studies Review. Child: Care, Health and Development, 40, 787-796. https://doi.org/10.1111/cch.12097

[10] King, G. and Chiarello, L. (2014) Family-Centered Care for Children with Cerebral Palsy Conceptual and Practical Considerations to Advance Care and Practice. Journal of Child Neurology, 29, 1046-1054.

[11] Pugin, A.J. (2008) The Relationship between Severity of Cerebral Palsy in Children and the Levels of Stress Experienced by Their Parents. http://hdl.handle.net/10539/5342

[12] Khayatzadeh, M. (2009) A Comparative Study about Quality of Life in Mothers of Children with Cerebral Palsy, Mental Retardation and Mothers of Normal Children. Shahed Journals System, 17, 49-58.

[13] Khayatzadeh, M.M., Rostami, H.R., Amirsalari, S. and Karimloo, M. (2013) Investigation of Quality of Life in Mothers of Children with Cerebral Palsy in Iran: Association with Socio-Economic Status, Marital Satisfaction and Fatigue. Disability and Rehabilitation, 35, 803-808. https://doi.org/10.3109/09638288.2012.708818

[14] Olawale, O.A., Deih, A.N. and Yaadar, R.K. (2013) Psychological Impact of Cerebral Palsy on Families: The African Perspective. Journal of Neurosciences in Rural Practice, 4, 159-163. https://doi.org/10.4103/0976-3147.112752

[15] Matuska, K.M. and Christiansen, C.H. (2008) A Proposed Model of Lifestyle Balance. Journal of Occupational Science, 15, 9-19. https://doi.org/10.1080/14427591.2008.9686602

[16] Cans, C. (2000) Surveillance of Cerebral Palsy in Europe: A Collaboration of Cerebral Palsy Surveys and Registers. Developmental Medicine \& Child Neurology, 42, 816-824. https://doi.org/10.1111/j.1469-8749.2000.tb00695.x

[17] Matuska, K. (2012) Description and Development of the Life Balance Inventory. OTJR: Occupation, Participation and Health, 32, 220-228. https://doi.org/10.3928/15394492-20110610-01

[18] Ware, J.E., Keller, S.D., Gandek, B., Brazier, J.E. and Sullivan, M. (1995) Evaluating Translations of Health Status Questionnaires: Methods from the IQOLA Project. International Journal of Technology Assessment in Health Care, 11, 525-551. https://doi.org/10.1017/S0266462300008710

[19] Aaronson, N., Acquadro, C., Alonso, J., Apolone, G., Bucquet, D., Bullinger, M., et al. (1992) International Quality of Life Assessment (IQOLA) Project. Quality of Life Research, 1, 349-351. https://doi.org/10.1007/BF00434949

[20] Wood, E. and Rosenbaum, P. (2000) The Gross Motor Function Classification Sys- 
tem for Cerebral Palsy: A Study of Reliability and Stability over Time. Developmental Medicine \& Child Neurology, 42, 292-296.

https://doi.org/10.1017/S0012162200000529

[21] Eliasson, A.-C., Krumlinde-Sundholm, L., Rösblad, B., Beckung, E., Arner, M., Öhrvall, A.-M., et al. (2006) The Manual Ability Classification System (MACS) for Children with Cerebral Palsy: Scale Development and Evidence of Validity and Reliability. Developmental Medicine \& Child Neurology, 48, 549-554.

https://doi.org/10.1017/S0012162206001162

[22] Crowe, T.K. and Florez, S.I. (2006) Time Use of Mothers with School-Age Children: A Continuing Impact of a Child's Disability. American Journal of Occupational Therapy, 60, 194-203. https://doi.org/10.5014/ajot.60.2.194

[23] Kaya, K., Unsal-Delialioglu, S., Ordu-Gokkaya, N.K., Ozisler, Z., Ergun, N., Ozel, S., et al. (2010) Musculo-Skeletal Pain, Quality of Life and Depression in Mothers of Children with Cerebral Palsy. Disability and Rehabilitation, 32, 1666-1672.

https://doi.org/10.3109/09638281003649912

[24] Johnson, C.B. and Deitz, J.C. (1985) Time Use of Mothers with Preschool Children: A Pilot Study. American Journal of Occupational Therapy, 39, 578-583. https://doi.org/10.5014/ajot.39.9.578

[25] McConnell, A.D., Futris, T.G. and Bartholomae, S. (2008) Mothers of Children with Physical Disabilities: Influence of Family Processes on Mothers' Depressive Symptomatology. Marriage \& Family Review, 45, 68-83. https://doi.org/10.1080/01494920802537522

[26] Laskar, A.R., Gupta, V.K., Kumar, D., Sharma, N. and Singh, M.M. (2010) Psychosocial Effect and Economic Burden on Parents of Children with Locomotor Disability. Indian Journal of Pediatrics, 77, 529-533. https://doi.org/10.1007/s12098-010-0064-7

[27] Tal-Hatu, K.H. and Mordi, E.L. (2007) Impact of Caring for Children with Cerebral Palsy on the General Health of Their Caregivers in an African Community. International Journal of Rehabilitation Research, 30, 191-194. https://doi.org/10.1097/MRR.0b013e3281e5af46

[28] Gevir, D., Goldstand, S., Weintraub, N. and Parush, S. (2006) A Comparison of Time Use between Mothers of Children with and without Disabilities. OTJR: Occupation, Participation and Health, 26, 117-127. https://doi.org/10.1177/153944920602600305 


\section{Appendix}

1) Sepideh Nazi, PhD student of Occupational Therapy, Department of Occupational Therapy, School of Rehabilitation Sciences, Iran University of Medical Sciences, Tehran, Iran;

2) *Narges Shafaroodi, PhD of Occupational Therapy, Department of Occupational Therapy, School of Rehabilitation Sciences, Iran University of Medical Sciences, Tehran, Iran;

3) Laleh Lajevardi, $\mathrm{PhD}$ of Occupational Therapy, Department of Occupational Therapy, School of Rehabilitation Sciences, Iran University of Medical Sciences, Tehran, Iran;

4) Afsoon Hassani Mehraban, $\mathrm{PhD}$ of Occupational Therapy, Department of Occupational Therapy, School of Rehabilitation Sciences, Iran University of Medical Sciences, Tehran, Iran;

5) Farzaneh Yazdani, PhD of Occupational Therapy, Faculty of Health and Life Sciences, Oxford Brookes University, Oxford, UK;

6) Samaneh Hosseinzadeh, PhD of Biostatistics, Department of Statistics and Computer Sciences, University of Social Welfare and Rehabilitation Sciences, Tehran, Iran. 